Velden, P.G. van der, Yzermans, J.C. Long-term effects of the terrorist attack in Beslan on adolescent
survivors. Journal of Clinical Psychiatry: 2009, 70(6), 934
\begin{tabular}{|l|l|}
\hline Postprint Version & 1.0 \\
\hline Journal website & http://article.psychiatrist.com/?ContentType=START\&ID=10004819 \\
\hline Pubmed link & http://www.ncbi.nlm.nih.gov/pubmed/19573489 \\
\hline DOI
\end{tabular}

This is a NIVEL certified Post Print, more info at http://www.nivel.eu

\title{
Long-Term Effects of the Terrorist Attack in Beslan on Adolescent Survivors
}

\author{
Peter G. van der Velden, Ph.D. Institute for Psychotrauma Diemen, The Netherlands Joris \\ C. Yzermans, Ph.D. Netherlands Institute for Health Services ReSearch Utrecht, The \\ NETHERLANDS
}

Sir: The important study by Moscardino et al. ${ }^{1}$ showed that adolescents who survived the Beslan terrorist attack (North Ossetia) did not report more overall levels of psychological distress (as measured with the Brief Symptom Inventory 18 and Strengths and Difficulties Questionnaire) 18 months after the event than a group of adolescents who were not in the school during the attack.

The authors conclude that these findings are in line with previous research suggesting that both directly and indirectly exposed children are at risk of developing adverse psychological symptoms after terrorisminduced trauma. However, a nonexposed control group was not included. Since the "normal” level of psychological distress among comparable nonexposed adolescents is unknown, this limitation severely hinders firm conclusions about the possible mid-term effects of the terrorist attack and may overestimate adverse affects. ${ }^{2}$

The cross-sectional nature of the study and the measures used prohibit any conclusion about the course or development of general psychological problems. Perhaps Moscardino and colleagues are right, but the reported data do not support their conclusion about the risk of developing adverse psychological symptoms. Of course, controlling for nonretrospective data on pre-event functioning is a powerful alternative, but in the case of such disasters, these data are hardly available. ${ }^{3}$ The only thing we are sure of is that both groups reported comparable levels of general psychological distress 18 months postevent. In addition, the high ethical standard of the researchers prevented the assessment of posttraumatic stress disorder - although Galea et al. ${ }^{4}$ showed that adverse effects of administering such measures might be very limited—and therefore it is unclear whether both groups are equally at risk for developing symptoms related specifically to the adverse event.

Although the nature of the trauma exposure was not comparable with that in the Beslan case, a 5-year longitudinal study ${ }^{5}$ (using the electronic medical records of general practitioners) of health effects among adolescents in a discotheque fire showed that in the first year youth both with and without burns presented many symptoms, psychological as well as physical. After 1 year, the problems of youth without burns decreased to the level of a matched control group. Apart from the societal situation in Beslan, it may be expected that problems will diverge in time between exposed and nonexposed adolescents. Nonexposed youth from the same community may be subjected to "the hierarchy of suffering," meaning that there is less attention for their problems.

Furthermore, a group of families surviving the attack were hosted or relocated for a 6-week period 3 months after the event in a private residential structure in Trento, Italy. The authors were contacted to provide psychological assistance. Disaster studies suggest that relocation, even during a relatively short period, might be a risk factor for postevent psychological disturbances. ${ }^{6}$ Being relocated with the expectation of returning after 6 weeks to a changed social system in which, according to one participant, "Now everyone follows his own path, not knowing which direction to take"1(p858) might be an important new source of stress. On the other hand, the 6-week period in Italy may have provided comfort, rest, and social support and helped to foster resilience and diminish stress,7 as was probably the aim of the 6- week hosting. Possible participation of adolescents in both groups in this 6-week relocation was not presented in the article, nor part of the analyses, although it may confound outcomes.

According to the researchers, this study is part of an ongoing project on the mental health of Beslan's children and families. As stated in the article, the number of studies examining the long-term psychological effects of such attacks is limited. We hope that the authors are able to conduct a follow-up study in which the aforementioned issues can be addressed. 
Velden, P.G. van der, Yzermans, J.C. Long-term effects of the terrorist attack in Beslan on adolescent survivors. Journal of Clinical Psychiatry: 2009, 70(6), 934

The authors report no financial or other relationship relevant to the subject of this letter.

\section{REFERENCES}

1. Moscardino U, Scrimin S, Capello F, et al. Psychological adjustment of adolescents 18 months after the terrorist attack in Beslan, Russia: a cross-sectional study. J Clin Psychiatry 2008;69:854-859

2. Rubonis AV, Bickman L. Psychological impairment in the wake of disaster: the disasterpsychopathology relationship. Psychol Bull 1991;109:384-399

3. Dirkzwager AJ, Kerssens JJ, Yzermans CJ. Health problems in children and adolescents before and after a man-made disaster. J Am Acad Child Adolesc Psychiatry 2006;45:94-103

4. Galea S, Nandi A, Stuber J, et al. Participant reactions to survey research in the general population after terrorist attacks. J Trauma Stress 2005;18:461-465

5. Dorn T, Yzermans CJ, Schilder A, et al. A cohort study of the longterm impact of a fire disaster on the physical and mental health of adolescents. J Trauma Stress 2008;21:239-242

6 . Uscher-Pines L. Health effects of relocation following disaster: a systematic review of the literature. Disasters 2009;33:1-22

7. Guay S, Billette V, Marchand A. Exploring the links between posttraumatic stress disorder and social support: processes and potential research avenues. J Trauma Stress 2006;19:327-338 